\title{
The View of Constructivist Theory on Assessment: Alternative Assessment Methods in Education
}

\author{
İrfan YURDABAKAN*
}

\begin{abstract}
Since the Ministry of National Education started the structural changes in the primary and secondary education curricula, there has been a growing interest towards constructivist learning philosophy, constructivist theory and active learning in educational and scientific environments in Turkey. Alternative assessment practices have an important place in the new curricula, which went into effect in 2005-2006 academic year. Many authors suggest that objectives for active learning method could only be attained if they were used together with alternative assessment practices. There are many writers who suggest that objectives for active learning method could only be reached if they were used together with alternative assessment activities. The principal aim of this study is to analyze the relations between constructivism and learning and assessment and also to discuss theoretically portfolio assessment and peer-self-co-assessment approaches that have emerged, and additionally to determine the positive and negative results stated in related studies, so that practitioners could draw some deductions.
\end{abstract}

Keywords: Constructivist theory, active learning, alternative assessment.

${ }^{*}$ Assist. Prof. Dr. DEU Buca Education Faculty, Department of Education Sciences, İzmir, Turkey. E-mail: irfan.ybakan@deu.edu.tr 


\section{SUMMARY}

The theory of constructivism, which has gained importance since the second half of the 20th century, provides a wide theoretical framework from design of learning settings to construction of assessment processes (Açıkgöz, 2003). Therefore today, while there is a shift from traditional to studentcentred learning settings, there are also innovations in assessment procedures, where the change is from summative assessment to formative assessment (Collins, 1991). The main purpose of this study is to describe the relationships among constructivist theory, active learning and assessment and to introduce the alternative assessment methods (co, self, peer and portfolio assessment) that have emerged and to display the positive and negative results found in related studies.

The theoretical framework that emerged with constructivism has caused learning settings to be student-centered and have triggered the assessment processes to include questioning of learning process. According to constructivists, knowledge is formed when an individual interacts with his/her environment (Açıkgöz, 2003). This idea sheds light on instructional practices necessary to obtain knowledge. Instructional practices should stress high level thinking and deep understanding, focus on real life problems, give importance to students' metacognitive knowledge and focus on improving reflective skills by making use of different assessment practices (Jonassen, 1994; Ernest, 1995; Honebein, 1996). This relationship between metacognitive knowledge and assessment has given rise to the birth of alternative assessment methods like portfolio, self-, peer and co-assessment.

Portfolio is defined as a purposeful, organized and systematic collection of students' products that tells the story of their efforts, developments and achievements in specific areas (Arter, Spandel \& Culham, 1995; Tedick \& Klee, 1998). The studies on portfolio assessment revealed that such practices improve students' class participation, cooperation, responsibility, high level thinking and reflective skills and help them become independent learners (Hamilton, 1994; Fenwick \& Parsons, 1999). However, some research findings have shown that it takes a long time and is an expensive assessment approach and there are concerns over the issues of reliability and validity since various types of many products are taken into account (Ediger, 2000; Erdoğan, 2006).

Self-assessment is defined as a method where students assess themselves according to criteria formed by the teacher or the ones chosen by the students among the other criteria (Dochy \& McDowell, 1997). Since individuals are at a more advantageous position than an outside observer to 
detect the changes about themselves, self-assessment could help the definition of those changes more realistically (Shrauger \& Osberg, 1981). Self-assessment improves students' self-criticism skills (Dochy \& McDowell, 1997), while it increases their level of perception of their weak and strong aspects (Boud \& Falchikov, 1989). One of the widespread opinions about self-assessment is the concern over students' giving higher scores to themselves. In a study done by Boud and Falchikov (1989), it was found that good students tend to score themselves lower while poor students tend to score themselves higher, students in higher classes can predict their achievements better than those in lower classes, and high-ability students' self-assessments are more realistic than those of low-ability students.

Peer assessment is the process where individuals in a group assess their peers (Boud, 1995; Falchikov, 1995). Peer assessment concentrates on two skills. First, assessment results of peers could be considered a part of selfassessment (Somervell, 1993). Second, peer assessment in group learning can help us focus on issues like student responsibility (Van den Berg, Admiraal and Pilot, 2006). In the assessment of cooperative skills and the learning from cooperation, peer assessment has an important influence. In their research, many authors have stated that peer assessment improves skills of criticism and learning levels of students working in groups (Freeman, 1995), and it encourages cooperation instead of competition (Orsmond, Merry and Reiling, 1996; Lejk \& Wyvill, 2001). On the other hand, Dancer and Dancer (1992) stressed that without an extensive training peers tend to assess themselves according to similarity, race and friendship, and there can be sham/tricky scoring because of reciprocity and secret agreement among members (Magin, 2001; Edgerton \& McKechnie, 2002).

Co-assessment is the instructor and the students assessing in cooperation during the learning process (Somervell, 1993). Co-assessment is gradually the responsibility of the instructor, but the students develop some skills about what is going to be assessed and how is it going to happen (Valencia, 1990). Co-assessment is used for three different purposes. First, coassessment is seen as summative assessment because it includes the instructor (Dochy, Segers and Sluijsmans, 1999). Second, co-assessment has an effect on the development skills of peer and self-assessment (Flavell, 1987; Falchikov, 1995). Third, co-assessment raises the quality of assessment by ensuring control over peer and self-assessment (Oldfield \& Macalpine, 1995).

The learning processes, where active learning methods are utilized, have given new responsibilities to students, have influenced their habits and behaviors, and have necessitated their education as "lifelong learners". At 
the same time this necessity has given rise to arguments of such concepts like "learning to learn" and "metacognitive knowledge". Metacognitive knowledge is individuals' questioning and management of their own learning and self-assessment has an important contribution to the development of this skill (Sundström, 2005). Portfolios, co- and peer assessment practices contribute a lot to the development of self-assessment skill. But, there is a need to see alternative assessment practices as part of learning process. Within this process, instructors are required to guide the students on definition or introduction of assessment criteria, on how the assessment will be carried out and on how those results will be utilized. 


\title{
Yapılandırmacı Kuramın Değerlendirmeye Bakışı: Eğitimde Alternatif Değerlendirme Yöntemleri
}

\author{
İfan YURDABAKAN ${ }^{*}$
}

ÖZ. Milli Eğitim Bakanlığı'nın ilk ve orta öğretim programlarında yapısal bir değişime gitmesi, Türkiye'deki eğitim ve bilim çevrelerinde yapılandırmacı kuram, aktif öğrenme ve alternatif değerlendirme gibi konulara duyulan ilgiyi artırmıştır. 2005-2006 öğretim yılında yürürlüğe giren yeni programda alternatif değerlendirme uygulamaları önemli bir yere sahiptir. Birçok yazar, aktif öğrenme yöntemlerinin alternatif değerlendirme uygulamalarıyla birlikte ele alınırsa amaçlarına ulaşabileceğini öne sürmektedir. $\mathrm{Bu}$ makalenin temel amacı yapılandırmacı kuram ile öğrenme ve değerlendirme arasındaki ilişkileri incelemek ayrıca, ortaya çıkan yöntemlerden öz, akran, ortak ve portfolyo değerlendirmeyi kavramsal açıdan tartışarak, uygulayıcıların çıkarsamalar yapabilmeleri için araştırmalarda ulaşılan olumlu ve olumsuz sonuçları saptamaktır.

Anahtar Sözcükler: Yapılandırmacı kuram, aktif öğrenme, alternatif değerlendirme.

\footnotetext{
* Yrd. Doç. Dr. İrfan Yurdabakan, DEÜ, Buca Eğitim fakültesi, Eğitim Bilimleri Bölümü, İzmir, Türkiye. E-posta: irfan.ybakan@deu.edu.tr
} 


\section{GíRiş}

Milli Eğitim Bakanlığı'nın eğitim programlarında yapısal bir değişime gitmesi, Türkiye'deki eğitim ve bilim çevrelerinde yapılandırmacı kuram, aktif öğrenme ve alternatif değerlendirme konularına duyulan ilgiyi artırmıştır. Bu ilgi, Türkçede alternatif durum belirleme (Kutlu, Yıldırım ve Bilican, 2009) olarak da ifade edilen alternatif değerlendirme yöntemleriyle ilgili araştırmalarda (Akçadağ, 2010; Anıl ve Acar, 2008; Birgin ve Gürbüz, 2008; Çakan, 2004; Güven ve Eskitürk, 2007) bir artışa neden olmuştur. Diğer yandan, makalenin ilerleyen bölümlerinde de ele alındığı gibi alternatif değerlendirme yöntemlerine dönük yurt dışında yapılmış çok sayıda araştırma vardır. Bu araştırmalar çoğunlukla, yeni yöntemlerle ilgili öğrenci algılarını, öğrenme ve öğrenme sürecine etkilerini, farklı değerlendirme yöntemleri arasındaki ilişkileri ve güvenirlik ve geçerlikleri gibi konuları içermektedir.

$\mathrm{Bu}$ yazının temel amac1, (1) yapılandırmacı kuram, aktif öğrenme ve değerlendirme arasındaki ilişkileri betimlemek, (2) ortaya çıkan alternatif değerlendirme yöntemlerinden öz, akran, ortak ve portfolyo değerlendirmeyi kavramsal açıdan ele almak ve (3) yapılan araştırmalarda bu yöntemlerle ilgili ulaşılan olumlu ve olumsuz sonuçları ortaya koymaktır. Bu amaçla, veri tabanları taranarak içerisinde yapılandırmacı kuram, aktif öğrenme ve alternatif değerlendirme yöntemlerinden öz, akran, ortak ve portfolyo değerlendirmenin geçtiği kaynaklara erişilmiş, bu kaynaklar incelenerek, yapılandırmacı kuramın öğrenme ve değerlendirmeye yaklaşımı ve öz, akran, ortak ve portfolyo değerlendirmeyle ilgili ulaşılan olumlu ve olumsuz sonuçları özetlenmeye çalışılmıştır.

\section{Yapılandırmacı Kuram, Aktif Öğrenme ve Değerlendirme İlişkisi}

Yapılandırmacılık, 20. yüzyılın ikinci yarısından itibaren Piaget, Vygotsky, Asubel, Bruner ve Von Glasersfelt gibi araştırmacıların yaptıkları araştırmalara bağlı olarak giderek önem kazanmaya başlamıştır (Açıkgöz, 2003). Yapılandırmacılık, öğrenme etkinliklerinin düzenlenmesinden değerlendirme süreçlerinin yapılandırılmasına kadar birçok konuda özgün ve uygulamaya dayalı kavramsal çerçevenin oluşmasına yol açmıştır. Oluşan bu kavramsal çerçeve, öğrenme ortamlarının, öğretmenin etkin, öğrencinin ise pasif ve daha çok alıcı konumunda olduğu geleneksel uygulamalardan öğrenci merkezliye doğru değişmesine yol açmıştır. Değerlendirme süreçleri ise alışılmış sınav uygulamalarına ek olarak öğrenme sürecini ve kişinin kendi öğrenmesini sorgulamaya dönük yenilikler içermeye başlamıştır (Collins, 1991). 
Ernest (1995), Heylighen (1993) ve Von Glasersfeld (1989)'e göre, bilgi felsefesi bilgiye ulaşılma süreciyle ilgilenir ve öğrenmenin nasıl gerçekleştiğini açıklamaya çalışır. Yapılandırmacı bilgi felsefesi de, bilginin doğası ve ona nasıl ulaşıldığı ile ilgilenmektedir. Buna göre bilgi, bireyin çevresiyle etkileşimi sırasında oluşur. Bu düşünce aynı zamanda bilgiye ulaşabilmesi için gerekli olan eğitimsel uygulamalara da yön gösterir. Yapılandırmacılar genelde, bireylerin geleneksel öğretim uygulamaları içerisinde bilgiyi keşfedemediklerini ve öğretmenlerin öğrettiği düşüncelerin nesnel gerçekliklerle yeterince uyuşmadığını iddia etmektedirler. Von Glasersfeld (1989), yapılandırmacılığı bilgi kavramına göre açıklar ve bilginin duyularla ya da iletişim yoluyla aktif olarak alındığını ve biliş tarafından yapılandırıldığını düşünmektedir.

Yapılandırmacılığın, öğrencilerin edilgen olduğu davranışçı öğrenme uygulamalarına alternatif olarak geliştiğine ilişkin güçlü bir görüş birliği vardır. Davranışçılık gözlenebilir davranışları vurgular, ifade ve düşüncenin anlamı üzerinde durmaktan kaçınır, yapılandırmacılık ise daha çok bilişsel yaklaşımı ele alır. Aradaki bu fark, yapılandırmacı öğrenme kuramının bütün yönleri için derin bir anlam taşır (Von Glasersfeld, 1989).

Yapılandırmacılar, kuramın farklı bileşenlerine ilişkin değişik bakış açıları ortaya koysalar da, öğrenme sürecine ve bu süreçte öğretmenlerin üstlenmeleri gereken rollerine ilişkin geniş bir uzlaşma vardır. Buna göre, ögretmenler bilgiyi aktaranlar değil, bilgiyi yapılandırmaları için öğrencileri güdüleyen, onlara firsatlar sunan, rehberlik eden ve anlamanın gerçekleştirilmesi için önemli rol oynayan kişilerdir (Driver, Aasoko, Leach, Mortimer ve Scott, 1994). Öğretmenler aynı zamanda eşgüdümcü, kolaylaştırıcı, kaynak önerici, özel eğitmen veya çalıştırıcıdır (Gergen, 1995).

Yapılandırmacı kurama göre, öğrenme ortamları öğreneni daha etkin kılmayı amaçlamalıdır. Fosnot (1996), öğretim hedeflerinin davranışlar veya beceriler yerine, kavram geliştirme ve derinlemesine anlama gibi noktalara odaklanması gerektiğini vurgulamıştır. Wilson ve Cole (1991), Jonassen (1994), Ernest (1995) ve Honebein (1996) gibi yazarlar ise öğrencilerin kavramsal birikimlerine uygun bir model oluşturma konusunda çeşitli öneriler geliştirmişlerdir. Bu önerilerin ortak yönleri şu şekilde sıralanabilir:

1.Gerçek yaşamda karşılaşılan problemlerin çözümü için uygulamalı etkinliklere odaklanılmalı ve gerçek yaşamla ilişkili öğrenme ortamları sağlanmalıdır.

2.Problem çözme, yüksek düzeyde düşünme ve derin anlama vurgulanmalı, öğretmen problemlerin çözümü için stratejileri analiz etmeli ve bu konuda öğrencilere yardımcı olmalıdır. 
3. Yaşamı çeşitli açılardan yorumlayabilmeleri için öğrencilere yardımcı olacak araçlar ve ortamlar oluşturulmalı, öğretmenler rehber, yansıtıcı, yardımcı ve kolaylaştırıcı rollerini üslenmelidirler.

4.Bilginin tekrarı ya da yeniden üretimine değil yapılandırılmasına odaklanılmalı ve bu konuda bireysel özellikler (öğrencinin var olan bilgisi, inançları ve tutumları), sosyal etkileşim ve işbirliği çabaları önemli bir yer tutmalidir.

5.Öğrenme, öğrenenler tarafindan gerçekleştirilmeli (öğrenci merkezi bir rol oynamalı) ve içsel olarak kontrol edilmelidir. O nedenle, öğrencilerin özdüzenleme (self-regulation) veya bilişüstü (metacognition) bilgilerine önem verilmelidir.

6.Öğrenme ortamlarında kullanılan öğrenme ve değerlendirme etkinlikleri ve kullanılan araçlar öz-çözümleme, öz-düzenleme, öz-yansıtma ve öz-farkındalık gibi bilişüstü becerileri geliştirmeye dönük olmalıdır.

7. Çoklu bakış açısı için farklı değerlendirme etkinliklerinden yararlanılmalı ve öz-değerlendirme konusunda öğrencilere deneyim sağlanmalıdır.

Farklı kaynaklar incelendiğinde bu listeyi uzatmak olanaklıdır. Ancak, vurgulananlardan iki önemli sonuç çıartılabilir. İlki, öğrenme sürecinde öğrenenin etkin bir rol alması gereğidir ki, bu gereklilik işbirlikli, probleme dayalı, projeye dayalı ve yaratıcı öğrenme gibi aktif öğrenme yöntemlerinin oluşmasını sağlamıştır. İkincisi ise, öğrenme sürecine etkin biçimde katılacak olan öğrencilerin sahip olması gereken özelliklerdir ki, bu özelliklerin başında bilişüstü bilgi veya öz-düzenleme stratejisi olarak nitelenen özellik gelmektedir (Açıkgöz, 2003). Bu özellik, aktif öğrenme ile değerlendirme etkinlikleri arasında bir takım ilişkilerin oluşmasına katkı sağlamıştır.

Perkins (1999), aktif öğrenme olarak nitelenen sürecin, sadece okuma ve dinleme değil, düşünceleri savunma ve paylaşma, denence kurma ve sorgulama gibi etkinlikler içermesi gerektirdiğini vurgulamıştır. Başka bir yazar aktif öğrenmeyi, öğrenenin öğrenme sürecinin sorumluluğunu taşıdığı, öğrenene öğrenme sürecinin çeşitli yönleriyle ilgili karar alma ve özdüzenleme yapma firsatlarının verildiği ve karmaşı öğretimsel işlerle öğrenenin öğrenme sırasında zihinsel yeteneklerini kullanmaya zorlandığ bir öğrenme süreci (Açıkgöz, 2003) olarak tanımlamıştır. De Corte (2000) ise aktif öğrenme ortamlarını, öğrencilere kişisel anlam taşıyan, özgün, anlaşılır ve açık uçlu problemler veya öğrenme malzemeleri sunan; derse duyulan ilgiyi arttıran, daha önceden edinilmiş bilgiyi güncelleyen ve etkinleştiren, anlamları belirginleştiren, aynı zamanda etkili öğrenme tekniklerinden ve yansıtma sürecinden yararlanmayı gerektiren ortamlar olarak nitelemiştir. Bu tanımlamalarda vurgulanan temel nokta, öğrencilerin 
öğrenme sürecine etkin katılımıdır. Etkin katılım, öğrenme süreciyle ilgili karar alma, yansıtma yapma ve öz-düzenleme becerileriyle yakından ilişkilidir. Çünkü aktif öğrenme süreci, yeterliklerinin farkında olan, ilerlemesi gereken konuların neler olduğunu bilen, nasıl ilerleyebileceği konusunda bilinçli, kendi öğrenmesini sorgulayan, yönlendiren ve yöneten bireyler gerektirmektedir. Bu gereklilik aktif öğrenme sürecinde kullanılan değerlendirme etkinliklerinin, öğrencilerin soruların çözümlemesini, yorumlamasını, değerlendirmesini yaptığı ve görüşlerini açıkladıkları bir oluşuma dönüşmesine yol açmıştır. Bu dönüşümün bir diğer nedeni de yaşam boyu öğrenme olgusudur. Bilişim teknolojilerindeki hızlı gelişme bilginin daha çabuk yayılmasına ve çoğalmasına neden olmuş, öğrenenin bilgi ve beceri edinimi formal eğitimin dışına taşarak, özellikle modern toplumlarda yaşam boyu süren bir etkinliğe dönüşmüştür. Bu etkinlik kişide öz-değerlendirme becerisini zorunlu kılmıştır. O nedenle Boud (1995), değerlendirme işleminin sadece not vermek için bir araç olmadığını, öğrencide gelişime yol açan ve gerektiğinde daha iyi öğrenme etkinliklerine yönlendirebilen bir süreç olması gerektiğine vurgu yapmıştır. Ancak, değerlendirme alanındaki alışılmış uygulamalar, tekrar ve mekanik alıştırmalar sonucunda edinilen bilgilerin test edilmesi şeklindedir. $\mathrm{Bu}$ şekilde yapılan değerlendirme, test kültürü denen oluşuma, bu kültürün gelişmesine ve birincil amaç olmasına neden olmuştur (Birenbaum, 1996). Benzer biçimde Dochy ve Moerkerke (1997) de, geleneksel test etme yöntemlerinin yaşam boyu öğrenme, eleştirel olma, problem çözme ve özdeğerlendirme gibi amaçlara yeterince uymayabileceğini vurgulamıştır. Boud (1990) ise etkin öğrenme ortamlarının, öğrenme ve değerlendirmenin iç içe geçtiği materyaller kullanılırsa amaçlarına ulaşabileceğini iddia etmiştir. Bu yüzden, etkin öğrenme ortamlarında kullanılan değerlendirme etkinlikleri öğrencilerin ilerleme aşamalarını, tamamlamaları gereken eksikliklerini görmelerini sağlayan ve öğrenme arac1 olarak öğrencilerin daha çok katılımını gerektiren bir oluşuma dönüşmüştür (Arter, 1996).

\section{Bilişüstü Bilgi ve Öz-değerlendirme İlişkisi}

Bloom'un hedeflerle ilgili sınıflaması üzerinde Anderson ve Krathwohl (2002)'un öncülüğünde yapılan yeni düzenlemede, bilişsel alan olarak nitelenen boyut, bilişsel süreç (cognitive process) ve bilgi olmak üzere iki boyutlu bir yapıya bürünmüştür. Bilişsel süreç hatırlama, anlama, uygulama, analiz, değerlendirme ve yaratma; bilgi ise olgusal, kavramsal, işlemsel ve bilişüstü bilgi olmak üzere alt boyutlara ayrılmıştır. Yeni sınıflama orijinalinden izler taşısa da, bilişsel süreç boyutu yaratma, bilgi boyutu ise bilişüstü bilgi gibi alt basamakları içermektedir. Bilgi basamağının altında 
yer alan bilişüstü bilgi, öğrenenin neyi bilip bilmediğine ilişkin düşünme, kendi öğrenmesini sorgulama ve düşünmesini yönetmesi becerisi (Dirkes, 1985) olarak tanımlanmaktadır. Flavell (1979), bu tanımlamaya ek olarak, bilişüstü bilginin öğrencinin, öğrenme ve düşünmeyle ilgili genel stratejiler bilgisi, farklı stratejilerin ne zaman/niçin kullanılacağını gösteren bilişsel görevler bilgisi ve edimin biliş ve güdüyle ilgili yönünü içeren öz-bilgi (selfknowledge) olmak üzere üç boyutu olduğunu belirtmiştir. Pickard (2007), Cornford, (2004) ve Edwards, Ranson ve Strain (2002) gibi yazarlar ise makalelerinde, bilişüstü bilginin yaşam boyu öğrenme olgusunun gelişiminde önemli bir öğe olduğunu ve bilişüstü bilgilerini sorgulayabilen bireylerin yaşamlarının ilerleyen dönemlerinde daha başarılı olabileceklerini ileri sürmüşlerdir. Başka bazı yazarlar ise bilişüstü, öz-bilgi ve özdeğerlendirme arasındaki ilişkiye dikkat çekerek, bilişüstü bilginin öz-bilgiyi kapsadığını; bireyin başarabilme konusundaki yeteneğini yargılamasının özbilgisini yargilaması anlamına geldiğini (Anderson ve Krathwohl 2002) ve öz-bilgisine dönük yargılama yapan bir bireyin öz-değerlendirme yapmış olacağını (Shrauger ve Osberg, 1981) ifade etmiş̧lerdir.

Öz-değerlendirme becerisinin geliştirilmesinde alternatif değerlendirme uygulamalarının önemli bir işlevi olduğu söylenebilir. $\mathrm{O}$ nedenle, yazının kalan bölümünde alternatif değerlendirme yöntemlerden öz, akran ve ortak değerlendirme üzerinde durulması uygun bulunmuştur. Ancak, hem süreç içerisinde öğrencilerin ilerleme aşamalarını göstermesi hem de öz, akran ve ortak değerlendirme firsatları yaratması bakımından portfolyo değerlendirmenin de ele alınmasında yarar görülmüştür.

\section{Portfolyo Değerlendirme}

İngilizce alanyazında "portfolio" olarak geçen kavram için Türkçe'de "ürün seçki dosyası" (Meb, 2003) ya da "bireysel gelişim dosyası" (Kutlu, Doğan ve Karakaya, 2008); "portfolio assessment" olarak geçen kavram için ise "tümel değerlendirme" (Öncü, 2009) ifadesinin kullanıldığ görülmektedir.

Konuyla ilgili olarak yapılan birçok çalışmada portfolyo veya portfolyo değerlendirme çeşitli yönleriyle ele alınıp tanımlanmıştır. Örneğin, portfolyo, öğrencilerin belirli alanlardaki çabalarının, ilerlemelerinin ve başarılarının öyküsünü anlatan ürünlerin amaçl1, örgütlü ve sistemli biriktirimidir (Arter, Spandel ve Culham, 1995; Tedick ve Klee, 1998). Paulson, Paulson ve Meyer (1991) portfolyoyu, öğrenmeyi geliştirmek için öğretim ve değerlendirme deneyimlerinin iç içe kullanılmasına izin veren, 
öğretim ve değerlendirmenin "kesişimi" olarak tanımlamaktadırlar. Grace (1992)'e göre portfolyo, öğrenme sürecinin geniş bir kaydıdır ve bu kayıtta öğrencinin ne öğrendiği, ne kadar ilerlediği, nasıl düşündüğüu, sorguladığı, çözümlediği, birleştirdiği, ürettiği ve diğer bireylerle bilişsel, duyuşsal ve sosyal olarak nasıl etkileşimde bulunduğuna ilişkin kanıtlar yer alır. Bir başka tanımda ise portfolyo, amacında öğrenci öğrenmesini ilerletmek olan ve öğrencilerin değişik bağlamlardaki gelişim kayıtlarının yansıtma ile çerçevelenen, işbirliği ile zenginleştirilen seçmeli biriktirimi (Wolf ve SiuRunyan, 1996) olarak ifade edilmektedir. Tanımlar incelendiğinde, portfolyoların bir amaca yönelik olması, öğrenme ve değerlendirmenin bir aracı olması ve ürünlerle ilgili yansıtmalara yer verilmesi gerektiği gibi bazı temel sonuçlara ulaşmak mümkündür. Ek olarak, tanımlarda portfolyonun “biriktirmek” eylemiyle ilişkisi açıkça görülebilir. TDK (2011)'nun Büyük Türkçe Sözlüğü’nde biriktirmek, (1) toplayıp yığmak, (2) bir şeyi ölçülü kullanarak artırmak, tasarruf etmek ve (3) öğrenme, yarar sağlama vb. sebeplerle bazı nesneleri bir araya getirmek, koleksiyon yapmak" şeklinde tanımlanmaktadır. Aynı sözlükte “-m, -1m, -im, -um, -üm” ekleri ise fiilden isim yapan eklerden birisi olarak gösterilmektedir. Buna göre, biriktirmek sözcügünden türetilen ve biriktirme işi veya biriktirilenlerin tutulduğu yer anlamına gelen biriktirim sözcüğünün portfolyonun karşılığı olarak kullanılabileceği düşünülmektedir. Bu çalışmada anlam karmaşasına yol açmamak amacıyla kullanılmamış olsa da sonraki araştırmacılar isterlerse portfolyo yerine biriktirim, portfolyo değerlendirme yerine ise biriktirim değerlendirme ifadelerini kullanabilirler.

Portfolyo değerlendirmeyle ilgili yapılan araştırmaların sonuçları çoğunlukla olumlu yönlerine vurgu yaparken, az bir kısmı da olumsuz yönlerine dikkat çekmektedir. Ulaşılan olumlu sonuçlar şöyle özetlenebilir: Portfolyo değerlendirme aracılığıyla yapılan yansitma ve öz-değerlendirme etkinlikleri öğrencilerin bilişüstü bilgilerini geliştirir (Hamilton, 1994). Portfolyo, öğrenenin sadece verilenler arasında doğruyu seçmesi yerine, bir alandaki yeterliliğini göstermesine (Calfee ve Perfumo, 1993) ve öğrenme ile değerlendirme etkinliklerini birleştirilerek (Moya ve O’Malley, 1994) özgün değerlendirme ortamlarının yaratılmasına olanak sağlar. Yaratıcılık, çeşitlilik ve öğrenenin özgürlüğe yönelmesini teşvik ederek ileri düzey düşünme becerilerini destekler (Hebert ve Schultz, 1996). Öğrenmeleri konusunda sorumluluk almaları için öğrencileri cesaretlendirir (Paulson vd., 1991), derse katılımı, işbirliği becerilerini ve öz-güven duygusunu geliştirir (Fenwick ve Parsons, 1999). Sınıf dışında da düşünme ve çalışmalarına olanak sağladığından (Zollman ve Jones, 1994), kendi kendilerini yönetebilen bağımsız öğrenenler olarak yetişmelerini destekler (Greaves ve Gupta, 2003). Öğrendiklerinin çok boyutlu yönlerini içeren (Paulson vd., 
1991) ve gurur duyabilecekleri ürünlerini gösterme firsatı sağlar (Dutt-Doner ve Gilman, 1998). Öğretmenleri öğrencileriyle birlikte işbirlikli yansıtma yapmaya yönlendirir (Pierce ve O’Malley, 1993), onların güçlü ve zayıf yönlerini görmelerine olanak verir (Chen, 1993). Öğretmenlere uygulamaları hakkında öğrencilerden, diğer öğretmenlerden, yöneticilerden ve ailelerden gelen çoklu dönüt sağlar (Faust ve Kieffer, 1995) ve öğretmen-öğrenci, öğretmen-ebeveyn ve öğrenci-ebeveyn arasındaki iletişime yardımcı olur (Calfee ve Perfumo, 1993).

Portfolyo değerlendirmenin bazı zorluklarına ilişkin ulaşılan araştırma sonuçları ise şu şekilde özetlenebilir: Portfolyo değerlendirme uzun zaman alan ve pahalı olan bir değerlendirme yöntemidir (Ediger, 2000; Gomez, 2000; Erdoğan, 2006). Değişik konulara yönelik olması ve çok sayıda ürünün biriktirilmesi nedeniyle geçerlik ve güvenirliğine ilişkin kanıt arama yolları testler veya diğer sınama yöntemlerine göre daha zayıf kalmaktadır (Ediger, 2000). Öğrenciler bazen nelerin yapılacağı veya biriktirileceği konusunda şüpheye düşebilir ya da biriktirme işlemleri için tanınan sürenin yeterli olmayacağı endişesine kapılabilirler (Fenwick ve Parsons, 1999). Her derse biriktirilen malzemeleri getirmelerini istemek öğrencileri sıkıntıya sokabilir veya getirmelerine rağmen üzerinde çalışılmaması ya da çalışılabilmesi için yeterli sürenin ayrılmaması sorun yaratabilir (Mullin, 1998). Biriktirilenler arasında öğrencinin çabasını temsil etmeyen ürünler yer alabilir veya kimi ürünler öğrenme amaçlarıyla yeterince örtüşmeyebilir (Arter ve Spandel, 1992). Çok çeşitli ürünlerin biriktirilmesi değerlendirme ölçütlerinin tanımlanmasını zora sokabilir. Bir ürünü değerlendirirken kullanılan ölçütler bir başka ürünü değerlendirmek için geçerli olmayabilir (Ediger, 2000; Erdoğan, 2006).

Sonuç olarak, öğrenmeye getirdiği katkılar nedeniyle portfolyo değerlendirmenin değerli bir uygulama olduğu söylenebilir. Ancak, en iyi verimin elde edilebilmesi için biriktirilenlerin dersin amaçlarına (hedef veya kazanımlarına) dönük ve öğrenciler tarafından oluşturulan ürünler olması önemlidir. Diğer yandan, biriktirilenler üzerinde öğrencilerin yansıtma yapmalarını sağlayacak uygulamalara yer verilmesi portfolyo değerlendirmenin amaçlarına ulaşmasını kolaylaştırabilir. $O$ yüzden, öğrenme sürecinde öğrencilerin biriktirilen ürünlerle ilgili "ne öğrendim, neyi iyi yaptım, bu ürünü neden seçtim, neyi düzeltmek/geliştirmek istiyorum" vb sorulara yanıt vermelerini ve yanıtları üzerinde tartı̧̧malarını sağlayacak uygulamalara ağırlık verilmelidir. Ayrıca daha fazla çıkarsamalar için Birgin ve Baki (2007), Fenwick ve Parsons (1999) Erdoğan (2006), Moya ve O'Malley (1994), Kutlu, Yıldırım ve Bilican (2009) ve Pierce ve O’Malley (1993)'in kaynaklarına başvurulmasında yarar olduğu söylenebilir. 


\section{Öz-değerlendirme (Self-assessment)}

Bu çalışmanın 2. bölümünde de ele alındığı gibi öz-değerlendirme bilişüstü bilgi olgusuyla yakından ilişkilidir. Bilişüstü bilgi öz-bilgiyi, özbilgi ise genel biliş bilgisi ve güdüsel inanç boyutlarını kapsar ve öğrenen öz-bilgisine dönük yargılama ve değerlendirme yaparsa, öz-değerlendirme yapmış olur (Shrauger ve Osberg, 1981). İlgili alanyazın incelendiğinde özdeğerlendirme konusunun kavramsal ve uygulamaya dönük yönleriyle ele alındığ1 görülebilir (Boud ve Falchikov, 2006; Sundström, 2005). Kavram olarak öz-değerlendirme, öğrenicilerin kendi öğrenmeleriyle ilgili yargılamalarda bulunmaları anlamına gelir (Boud ve Falchikov, 1989). Bir başka tanımda öz-değerlendirme, öğretmenin oluşturduğu ölçütler veya bu ölçütler içerisinden öğrenciler tarafından seçilenlere göre öğrencilerin kendilerini değerlendirdikleri bir yöntem olarak ifade edilmektedir (Dochy ve McDowell, 1997).

Öz-değerlendirme konusunu içeren birçok makalede yararlarına ilişkin görüş ve bulguların yanı sıra, isabetli (doğru) yapılıp yapılmadığına ilişkin sonuçlar da tartışılmaktadır. Öz-değerlendirmenin bireye sağladığı yararlar kısaca şöyle özetlenebilir: Öz-değerlendirme, öğrencilerin öz-eleştiri becerisini geliştirir (Dochy ve McDowell, 1997). Çeşitli becerilere dönük olarak yapılan öz-değerlendirme, öğrencilerin bu yönde deneyim kazanmalarını sağlar ve deneyimli öğrenciler etkili öğrenenler olarak görülebilir. Ayrıca, bu öğrencilerin güçlü ve zayıf yönlerine ilişkin algı düzeyleri daha gerçekçidir (Boud ve Falchikov, 1989). Kişi kendisiyle ilgili çıkarımlar konusunda dışarıdan bir gözlemciden daha fazla bilgiyi özdeğerlendirme sayesinde edinebilir ve öz-değerlendirme kişideki değişimin daha gerçekçi biçimde tanımlanmasına yardımcı olur (Shrauger ve Osberg, 1981). Öz-değerlendirme, öğrencilere öğrenmelerini geliştirmeleri bakımından yardım sağlamanın önemli bir yoludur. Çünkü özdeğerlendirme, öğrencilerin kendi öğrenmelerinin bilişüstü boyutlarına odaklanmalarını sağlayarak, edimlerini izlemeleri konusunda eğitir. Özdeğerlendirme, aynı zamanda öğrenencilerin öğrenme için izlemiş oldukları stratejilerinin etkililiğini, öğrenme derecelerini ve ileriki sınıflarda kullanabilecekleri öğrenme stratejilerini geliştirir (Dochy, Segers ve Sluijmans, 1999).

Öz-değerlendirmeyle ilgili yaygın görüşlerden birisi bireyin kendisine olduğundan yüksek puan vereceği kaygısıdır. Boud ve Falchikov (1989) tarafindan yapılan bir araştırmada, öğrencilerin öz-değerlendirme puanlarının bir ölçütle karşılaştırılmasını içeren çalışmalar analiz edilmiştir. Ulaşılan sonuçlara göre, iyi öğrencilerin kendilerini az, zayıf öğrencilerin ise çok puanlandırmaya eğilimli oldukları ayrıca, üst sınıflardaki öğrencilerin 
kendi başarılarını alt sınıftakilere oranla daha iyi tahmin edebildikleri ve yetenekli öğrencilerin daha düşük yeteneklilere oranla gerçekçi özdeğerlendirme yaptıkları bulunmuştur. Fakat Kaufman, Felder ve Fuller (1999) tarafından yapılan bir başka araştırmada öz-değerlendirme konusunda iyi yetiştirilen öğrencilerde böyle bir eğilimin gözlenmediği, örneğin akranların değerlendirmesiyle öz-değerlendirmeler arasında yüksek uyumun olduğu sonucuna ulaşılmışlardır. Öte yandan, bazı yazarlar değerlendirilen yeteneğin öz değerlendirme üzerinde etki yaratacağını ileri sürmüşlerdir. Buna göre, yetenek alanı zorlaştıkça öz-değerlendirmenin isabetliliğinin azalacağı, kolaylaştıkça da artacağı iddia edilmiştir (Ackerman, Beier ve Bowen, 2002). Ek olarak, kullanılan ölçeklerin öz-değerlendirmeler üzerinde etki yaratacağını iddia eden görüşler de vardır. Buna göre, değerlendirilecek alanın iyi tanımlanamadığı ve genel soruların yer aldığı ölçeklerle yapılan öz-değerlendirmelerde öğrencilerin kendilerine fazla puan verdikleri ancak, becerilerin açıkça tanımlandığı ve daha özel soruların yer aldığı ölçeklerle yapılan öz-değerlendirmelerde ise daha gerçekçi sonuçlara ulaşıldığı belirtilmiştir (Ackerman vd., 2002). Öz-değerlendirme becerisinin cinsiyetle ilişkisini çalışan araştırmalar ise, erkeklerin kendi yeteneklerini olduğundan daha yüksek, kızların ise daha düşük değerlendirdiğini göstermiştir (Shen ve Pedulla, 2000).

Sonuç olarak, ülkemizde eğitim programlarının yapılandırmacı kurama göre değiştirilmiş olması, öğrencilerin öğrenme sürecine etkin katılımlarını ve öğrenmeleri için daha çok sorumluluk almalarını zorunlu kılmıştır. Bu zorunluluk, öğrenme konusundaki davranış ve alışkanlıklarını da etkilemiştir. Etkin öğrenme uygulamaları kişinin kendi öğrenmesini sorgulama ve yönetmesi becerisini gerekli kılmıştır. 2005-2006 öğretim yılında yürürlüğe giren yeni programda süreç içerisinde öz-değerlendirme uygulamalarına yer verilmiş olması, uzun dönemde söz konusu becerilerin geliştirilmesi üzerinde etki yaratabilir. Ancak, bu etkinin sağlanabilmesi, büyük ölçüde uygulayıcıların öz-değerlendirme konusundaki bilgi, beceri ve tutumlarına bağlidır.

\section{Akran Değerlendirme (Peer Assessment)}

Akranlar arasında dönüt alışverişi sağlaması nedeniyle son yıllarda özellikle grup çalışması sırasında akran değerlendirmeye duyulan ilgide önemli bir artışın olduğu gözlenmektedir (McMahon, 2009). Akran değerlendirme, bir grup içerisinde yer alan bireylerin akran veya akranlarını değerlendirmesi süreci (Boud, 1995; Falchikov, 1995; Freeman, 1995) olarak tanımlanmaktadır. Akran değerlendirme sadece bir puanlama ya da 
değerlendirme işlemi değil, aynı zamanda becerilerin geliştirildiği bir öğrenme sürecidir (Boud ve Falchikov, 2006; Somervell, 1993).

Akran değerlendirme temel olarak iki beceri üzerine odaklanır. İlki, akranların değerlendirme sonuçları öz-değerlendirmenin bir parçası gibi görülebilir ve öz-değerlendirme becerisini doğrudan, bilişüstü beceriyi de dolaylı olarak etkileyebilir (Flavell, 1987; Somervell, 1993; Topping, 2005). İkincisi ise, grupla ögrenmede grup işlerine katılım ve sorumluluk alma gibi becerilerin geliştirilmesine olanak sağlar (Van den Berg, Admiraal ve Pilot 2006). Birçok yazar (Boud, 1995; Falchikov, 1995; Freeman, 1995; Topping, 2005), akran değerlendirmeyle işbirliği becerisi arasındaki ilişkiye vurgu yaparak, akran değerlendirmenin soysal etkileşim, bireysel değerlendirilebilirlik ve olumlu bağımlılık gibi işbirliği koşullarının yerine getirilmesinde etkili olabileceğini belirtmişlerdir.

Akran değerlendirme, hem işbirliği becerilerinin hem de işbirliğinden gelen öğrenmelerin değerlendirilmesinde etkili bir yol olabilir (Yurdabakan, 2010). Ayrıca, grup çalışması için eşit çaba ve katılımın sağlanmasında ve takım sorumluluklarını yerine getiremeyen öğrencilerin kontrol edilmesinde (Kaufman vd. 1999) etkili olan bir yöntemdir. Öte yandan, yaşam boyu öğrenme olgusu bireyin bir grup içerisinde çalışmasını gerektirebilir ve akranlar edim ve gelişimlerini değerlendirmek zorunda olabilirler. Akran değerlendirme, bireylerin başkalarından dönüt alma-verme becerileri konusunda deneyim kazanmalarına yardımcı olur (Flavell, 1987; Topping, 2005). Bunun gibi başka birçok araştırmacı yaptıkları çalışmaların sonucunda akran değerlendirmenin çeşitli yararlarını ortaya koymuşlardır. Örneğin, Weaver ve Cotrell, (1986), akran değerlendirmenin öğrencilere ölçütler ve ölçütlerin saptanması konusunda içten bir bakış açısı sağlayarak, grubun çalışma konusunda verimliliğini artırdığını ifade etmişlerdir. Freeman (1995); Lejk ve Wyvill (2001); Lourdusamy ve Divaharan (2000); Orsmond, Merry ve Reiling (1996); Purchase (2000) gibi araştırmacılar, akran değerlendirmenin grup görevlerine katılımı teşvik ederek öğrenme üzerinde yoğunlaşılmasını sağladığını, derse devamı artırarak öğrencilere sorumluluğu öğrettiğini, üyeler arasındaki etkileşim nedeniyle eleştirel yetenekleri geliştirdiğini ve yarışmaya karşın işbirlikli öğrenmeyi teşvik ettiğini ortaya koymuşlardır. Yueh ve Alessi (1988) ise öğrencilerin öğrenme sürecinde etkin rol almalarının bir yolunun derse olan ilgiyi ve katılımı ödüllendirmek olduğunu, bu amaçla akran değerlendirme uygulamalarının önemli bir görevi yerine getirebileceğini ifade etmişlerdir. Boud ve Falchikov, (2006); Falchikov (1995); Freeman, (1995); Keaten ve Richardson (1992) ve Pond, Ul-Haq ve Wade, (1995) gibi birçok yazar ise yaptıkları araştırmalarda, akran değerlendirmenin öğrencileri teşvik edici ve 
güdüleyici, görevleri yerine getirmeyen öğrencileri denetlemede de etkili bir yol olduğu sonucuna ulaşılmışlardır.

Özetlenen araştırma sonuçları, öğrencilerin öğrenme ve değerlendirme sürecine etkin katılımlarını sağlaması nedeniyle, akran değerlendirmenin değerli bir uygulama olduğunu göstermektedir. Buna karşın, kimi yazarlar akran değerlendirme uygulamalarına ilişkin endişelerini ifade etmektedirler. Örneğin, Dancer ve Dancer (1992), eğer kapsamlı bir eğitim verilmemişse, akranların benzerlik, ırk ve arkadaşlığa dayalı değerlendirmeler yapmaya eğilimli olabileceklerini, bu şekilde yapılan akran değerlendirmelerin yüksek puanlama ile sonuçlanabileceğini vurgulamışlardır. Akran değerlendirme ile ilgili bir başka endişe, karşılıklılık ve gizli anlaşma nedeniyle üyeler arasında danışıklı/hileli puanlama olabileceği ve bu durumun grubun üyeleri arasında ayırıcı olmayan değerlendirmelere yol açabileceği endişesidir (Edgerton ve McKechnie, 2002; Magin, 2001 ve Parsons ve Drew, 1996). Ayrıca, grupta baskın olan bireyin gruba egemen olması nedeniyle güç (desibel) puanlaması ya da güçlüye dönük puanlama da denen bir değerlendirme durumunun oluşması riski vardır. $\mathrm{Bu}$ şekilde yapılan değerlendirmeler baskın olan bireyin hak etmediği halde yüksek puan almasına neden olabilir. Dile getirilen bir diğer endişe ise parazit puanlama riskidir. Parazit puanlama, bazı öğrencilerin grup işlerine katkısı olmadığı halde grubun puanlarından yararlanma durumudur (Pond vd., 1995). Ayrıca, değerlendirme sonuçlarına diğer üyelerin içerleyebileceği, üyeler arasında çatışma ve sonraki uygulamalarda misillemeye neden olabileceği kaygısı (Kaufman vd., 1999) tartışılan endişeler arasında yer almaktadır. Kimi yazarlar (Birenbaum ve Dochy, 1996; Kaufman vd.,1999; McDowell, 1995) yaptıkları çalışmalarda, arkadaşlık, cinsiyet ve benzerlik faktörünün değerlendirmeler üzerinde güçlü bir etki yaratmadığını; diğerlerinin sırtından geçinen öğrencilerin sayısında önemli ölçüde azalma olduğunu ortaya koymuş olsalar da, benzer konuların incelenmesi için daha fazla araştırmaya gereksinme olduğu söylenebilir. Diğer yandan, Dochy vd., (1999) akran değerlendirmenin yukarıda siralanan sınırlılıklarının önüne, özdeğerlendirme ya da ortak değerlendirme etkinlikleriyle birlikte kullanılarak geçilebileceğini ifade etmişlerdir.

\section{Ortak Değerlendirme (Co-assessment)}

İngilizce alan yazında common, collaborative ya da co-assessment olarak geçen ortak değerlendirme, öğrenme sürecinde öğretmen ve öğrencilerin işbirliği içerisinde değerlendirmeyi birlikte gerçekleştirmeleri anlamına gelmektedir (Somervell, 1993). Öğretmen ve öğrencilerin birlikte değerlendirme ölçüt ve standartlarını tanımlamaları nedeniyle ortak değerlendirme öğrenciler için bir ögrenme süreci olarak da görülür. Ortak 
değerlendirmede çoğunlukla öğretmenin sorumluluğu ön plandadır, ancak öğrenci bu süreçte neyin nasıl değerlendirileceği konusunda beceri geliştirir. Valencia (1990)'ya göre, öğretmen ve öğrencilerin birlikte işbirliği içinde gerçekleştirdikleri değerlendirme yaklaşımı, öğrenmede ortaklığı ilerletir ve içerik, ölçüt belirleme, puanlandırma, bire bir tartışma ve şekillendirme gibi değişik durumlarda öğretmen ve öğrencilerin birlikte çalışmalarına olanak hazırlar. Böylece ortak değerlendirme, öğretmenlere final değerlendirmelerinde gerekli olan kontrolü ellerinde bulundurmalarını sağlarken, öğrencilere de kendilerini değerlendirme ve değerlendirme becerilerini geliştirmeleri konusunda firsatlar sunar (Hall, 1995).

Diğer yandan, ilgili alanyazın kapsamlı bir biçimde incelendiğinde, ortak değerlendirmenin üç farklı amaç için ele alındığı görülebilir. İlki, ortak değerlendirme, öz ve akran değerlendirmeden farklı olarak, içinde öğretmenin de yer alması nedeniyle düzey belirlemeye dönük değerlendirme gibi ele alınmaktadır (Dochy vd., 1999). Ancak, ortak değerlendirme, öğretmenlerin öğrencileriyle işbirliği yapmalarını gerekli kıldığından, öğrencilerin değerlendirme konusunda sorumlulukları olmadığı halde, sürece etkin katılımlarını sağlayarak, nelerin nasıl değerlendirileceği konusunda düşüncelerini almayı ve değerlendirme konusunda becerilerini geliştirmeyi amaçlar (Somervell, 1993). İkincisi, ortak değerlendirme, öz ve akran değerlendirme becerisini etkilemektedir. Çünkü birçok yazar, ortak değerlendirmenin öz ve akran değerlendirmenin bir parçası gibi görülebileceğini, bu yüzden ortak değerlendirme etkinliklerinin öz ve akran değerlendirme becerisinin gelişimini olumlu yönde etkileyebileceğini ileri sürmektedir. Örneğin, Falchikov (1995), Flavell (1987) ve Freeman (1995) gibi yazarlar, özetle, ortak değerlendirmenin akran, akran değerlendirmenin ise öz-değerlendirme üzerinde olumlu etki yaratacağını, öğrencilerin öz ve akran değerlendirme eğitimine ortak değerlendirme etkinlikleriyle başlanabileceğini savunmaktadırlar. Üçüncüsü ise, ortak değerlendirme öz ve akran değerlendirmenin kontrollü bir biçimde yapılmasını sağlayarak, öz ve akran değerlendirmelerin kalitesini yükseltebilir düşüncesidir. Öz ve akran değerlendirmelerin yukarıda sözü edilen sınırlılıkları nedeniyle, değerlendirme yöntemlerinin birleştirilerek uygulanmasına dönük çalışmalar yapılmıştır. Bu çalışmaların çoğu, öz ve akran değerlendirmelerin öğrenme ve öğrenci açısından adilliğine, doğruluğuna ve olumlu etkilerine ulaşabilmek için yollar arar niteliktedir. $\mathrm{Bu}$ amaçla yapılan birçok çalışmanın bulguları (Falchikov, 1986; Hall, 1995; Horgan, Bol ve Hacker, 1997; Oldfield ve Macalpine, 1995; Stefani, 1992 ve Strachan ve Wilcox, 1996) öz, akran ve ortak değerlendirme etkinliklerinin birlikte kullanımının etkili sonuçlar verdiği yönündedir. Somervell (1993), öz, akran ve ortak değerlendirmelerin birlikte kullanımının öğrenci ve öğretmen etkileşimini 
artırdığını, öğrencilerin girişimcilikle ilgili yeterliliklerini geliştirmede oldukça önemli olduğunu ve daha fazla güdülenme ve "derin" öğrenmeye olanak sağladığını vurgulamıştır.

Sonuç olarak, özellikle akran ve öz-değerlendirme uygulamalarını geliştirmesi bakımından ortak değerlendirmenin değerli bir uygulama olduğu söylenebilir. Öğrenciler bu sayede değerlendirme konusunda öğretmenleriyle birlikte çalışma firsatı bulurlar. Bu birliktelik öğretmene değerlendirmede önceliği elinde bulundurmasını sağlarken, öğrencilere ölçütleri saptama ve puanlama konusunda derin bir anlayış kazandırır. Ayrıca, değerlendirmeye konu olan ölçütlerin saptanması öğrenciler için öğrenilecek olan amaçları da görmelerini sağlar. $\mathrm{Bu}$ durum öğrencilere öğrenimlerinin ilerleyen dönemlerinde hem öğrenme hem de değerlendirme konusunda önemli avantajlar getirir. Ek olarak, ortak değerlendirme, öz veya akran değerlendirme uygulamalarına yer verilen etkinliklerde bu tür değerlendirmelerin daha adil ve tutarlı biçimde yapılması için öğretmene kontrol olanağı sağlar.

\section{SONUÇ, TARTIŞMA VE ÖNERILER}

Bilgi teknolojilerindeki gelişim, bilginin yayılması ve bilgiye ulaşılması konusunda hılı değişimlere neden olmuştur. $\mathrm{Bu}$ değişim, bireyin öğrenmesine olan bakış açısını da etkilemiştir. O yüzden, öğrenme ortamları geleneksel olandan öğrenci merkezliye doğru geçiş göstermiş, birçok ülke eğitim programlarında aktif öğrenme yöntemlerinin uygulanmasına dönük yeniliklere gitmeye başlamıştır. Aktif öğrenme yöntemlerinin uygulandığ öğrenme süreçleri, öğrencilere öğrenmeleri konusunda yeni sorumluluklar yüklemiş, alışkanlıklarını ve davranışlarını etkileyerek, onların birer "yaşam boyu öğrenenler" olarak yetiştirilmesini zorunlu k1lmıştır. Bu zorunluluk aynı zamanda "öğrenmeyi öğrenme" ve "bilişüstü bilgi" gibi kavramların tartı̧̧1masına neden olmuştur.

Aktif öğrenme, öğrenmeyi öğrenme, yaşam boyu öğrenme ve bilişüstü bilgi arasında güçlü ilişkiler vardır. Bilişüstü bilgi kişinin kendi öğrenmesini sorgulamas1 ve yönetmesi olarak tanımlandığına göre, bu becerinin geliştirilmesinde öz-değerlendirmenin önemli bir payı olduğu söylenebilir. Sundström (2005), öz-değerlendirmenin bireylerin kendileriyle ilgili çıkarımlarda bulunmalarına katkı getiren önemli bir beceri olduğunu vurgulamıştır. Birçok araştırmacı, portfolyo, ortak ve akran değerlendirmenin yukarıda değinilen yararlarının yanı sıra, temel olarak öğrenme ve öz-değerlendirme becerisinin geliştirilmesine katkı getirmek olduğunu savunmuşlardır. Bu açıdan ele alınırsa, amacına ulaşabilmesi için alternatif değerlendirme uygulamalarının öğrenme sürecinin bir parçası gibi 
görülmesine gereksinim vardır. $\mathrm{Bu}$ süreçte, öğretmenlerin değerlendirme ölçütlerinin tanımlanması veya tanıtılması, değerlendirmenin nasıl yapılacağı ve sonuçlarından nasıl yararlanılacağı gibi konularda beceri kazanmaları için öğrencilerine rehberlik etmeleri beklenir. Diğer yandan, uygulamaların amaçlarına ulaşabilmesi için uygulayıcıların alternatif değerlendirme yöntemleri konusundaki bilgi, beceri ve tutum düzeylerinin geliştirilmesine gereksinim vardır. Çünkü Türkiye'de konuyla ilgi yapılan araştırmaların birçoğu (Akçadağ, 2010; Anıl ve Acar, 2008; Duban ve Küçükyılmaz, 2008; Gelbal ve Kelecioğlu, 2007) alternatif değerlendirme uygulamaları konusundaki sorunların hala devam ettiğini göstermektedir. Sorunun çözümüne katkı getirmesi amacıyla uygulayıcıların öz, akran ve ortak değerlendirme konusundaki gereksinmelerini saptamak amaciyla daha çok araştırmanın yapılmasında yarar olacağı söylenebilir. Öte yandan, öğretmen yetiştiren kurumlarda bu amaçla okutulan derslerin içeriği alternatif değerlendirme yöntemlerini daha kapsamlı biçimde ele alacak şekilde genişletilerek, öğretmen adaylarının konuyla ilgili bilgi ve beceri düzeyleri geliștirilebilir.

Alternatif değerlendirme uygulamalarına ilişkin uluslararası alan yazın incelendiğinde, bu tür değerlendirmelerin çoğunlukla yüksek öğretim düzeyinde ele alındığı görülmektedir. Bunun yanında, birçok araştırmacı yukarıda sıralanan nedenlerden ötürü alternatif değerlendirme uygulamalarının önemli uygulamalar olduğunu da ifade etmektedirler. Ancak, alternatif değerlendirme uygulamalarının özellikle geçerlik ve güvenirliğine ilişkin endişeler başlıca konular arasında yer almaktadır. Dochy vd. (1999) ve Cho ve Schunn (2003) gibi yazarlar, alternatif değerlendirme uygulamalarının geçerli ve güvenilir olup olmadığının bilinmesine ve geliştirilmesine veya var olan uygulamaların yeniden ele alınmasına gereksinim olduğunu vurgulamışlardır. Çalışmalarda alternatif değerlendirme yöntemlerinin geçerlik ve güvenirliğine ilişkin kanıt arama yolları farklıl1k göstermektedir (Boud, 1995; Dancer ve Dancer, 1992; Oldfield ve Macalpine, 1995; Orsmond vd., 1996; Topping, 1998). Örneğin, Dochy vd. (1999) akran değerlendirmeyle ilgili araştırmaları analiz ettikleri çalışmalarında, akran değerlendirmenin güçlüklerine ilişkin temel bulguları geçerlik, adillik, doğruluk (güvenirlik) ve etkileri olmak üzere dört başlık altında sınıflamışlardır. Karşılıklılık, gizli anlaşma, ortak paylaşılan değerler, görünüşten etkilenme, inanç, cinsiyet ve 1rk farkl1l1kları gibi faktörleri akran değerlendirmenin geçerlik, geleneksel değerlendirmelerle karşılaştırıldığında dürüstlüğ̈̈ konusundaki öğrenci algılarını adillik, akran değerlendirme ile öğretmen değerlendirmesi arasındaki uyumu doğruluk (güvenirlik) ve akran değerlendirmenin grup ve bireylerin başarısı ve tutumu konusundaki yararlarını etkisi kavramlarıyla ilişkilendirmişlerdir. Diğer yandan, 
Yurdabakan'a (2008) göre, Boud (1995) ve Messick (1995) alternatif değerlendirme yöntemleri için sonuçsal geçerlik (consequential validity) kavramını gündeme getirmişlerdir. Buna göre sonuçsal geçerlik, değerlendirmenin öğrenme üzerindeki etkisine dayanarak açıklanabilir. Eğer, alternatif değerlendirme uygulamaları öğrencilerin öğrenmeleri üzerinde beklenen etkiyi sağlıyorsa, uygulamanın geçerliğinden söz edilebilir. $\mathrm{Bu}$ durumda, öğrenme sürecinde uygulanan öz, akran veya portfolyo değerlendirme sonuçları amaca göre alışılmış değerlendirme sonuçlarıyla ya da öğrencilerin bilişüstü bilgi düzeyleriyle karşılaştırılarak sonuçsal geçerlik konusunda kanıt elde edilebilir. Bu konuyla ilgili daha fazla bilgi için Boud, (1995) ve Messick (1995)'in kaynaklarına başvurulabilir.

\section{KAYNAKLAR}

Ackerman, P. L., Beier, M. E., \& Bowen, K. R. (2002). What we really know about our abilities and our knowledge. Personality and Individual Differences, 33, 587-605.

Açıkgöz, K. (2003). Aktif Öğrenme. Kanyılmaz Matbaası, İzmir

Akçadağ, T. (2010). Öğretmenlerin İlköğretim Programındaki Yöntem Teknik Ölçme ve Değerlendirme Konularına İlişkin Eğitim İhtiyaçları. Bilig, Say1 53: 29-50

Anıl, D. ve Acar, M. (2008). Sınıf Öğretmenlerinin Ölçme Değerlendirme Sürecinde Karşılaştıkları Sorunlara İlişkin Görüşleri. Yüzüncü $Y l l$ Üniversitesi, Ë̆itim Fakültesi Dergisi.(5),2, 44-61

Anderson, L. W. \& Krathwohl, D. R. 2002. A Revision of Bloom's Taxonomy: Theory into Practice, 41(4).

Arter, J. A. (1996). Using assessment as a tool for learning. In R. Blum \& J. Arter (Eds.), Student performance assessment in an era of restructuring (pp. 1-6). Alexandria, VA:

Arter. J. A. \& Spandel, V. (1992). Using Portfolios of Student Work in Instruction and Assessment. Educational Measurement: Issues and Practice, 11(2).

Arter, J. A., Spandel, V. \& Culham, R. (1995). Portfolios for Assessment and Instruction. ERIC Doküman1, Servis Numaras1: ED 388890.

Birenbaum, M. (1996). Assessment 2000: towards a pluralistic approach to assessment. In M. Birenbaum, \& F. Dochy (Eds.), Alternatives in assessment of achievements, learning processes and prior knowledge (3-29). Boston, MA: Kluwer. 
Birenbaum, M., \& Dochy, F. (1996). Alternatives in Assessment of Achievement, Learning Processes and Prior Knowledge, 3-31 (Boston, MA, Kluwer Academic).

Birgin, O. ve Baki, A. (2007). The Use of Portfolio to Assess Student's Performance. Journal of Turkish Science Education. 4(2), 75-90

Birgin, O. ve Gürbüz, R. (2008). Sınıf Öğretmeni Adaylarının Ölçme ve Değerlendirme Konusundaki Bilgi Düzeylerinin İncelenmesi. S. $\ddot{U}$. Sosyal Bilimler Enstitüsü Dergisi. 20, 163-179.

Boud, D. 1990. Assessment and the promotion of academic values. Studies in Higher Education, 15, 101-111.

Boud, D. (1995) Enhancing Learning through Self Assessment. Kogan Page, London.

Boud, D. \& Falchikov, N. (1989) Quantitative studies of self-assessment in higher education: a critical analysis of findings, Higher Education, 18, 529-549.

Boud, D., \& Falchikov, N. (2006). Aligning Assessment with long-term learning, Assessment and Evaluation in Higher Education, 31(4), 399413.

Calfee, R. \& Perfumo, P. (1993). Student Portfolios: Opportunities for a Revolution in Assessment. Journal of Reading, 36(7), 532-537.

Chen, L.M. (1993). Portfolios in Second and Foreign Language Classroom Assessment.http://spectrum.troy.edu/ lchen/papers/portfolio.doc (Erişim: 21.10.2005).

Cho, K., \& Schunn, C. (2003). Validity and reliability of peer assessments with a missing data estimation technique. World Conference on Educational Multimedia, Hypermedia and Telecommunications.(1), 1511-1514.

Collins, A. (1991). The role of computer technology in restructuring schools. Phi Delta Kappan, 41-56.

Cornford, I. R. (2004). Cognitive and metacognitive learning strategies as a basis for effective lifelong learning: How far have we progressed? Paper presented to the Australian Association for Research in Education Conference, Melbourne. http://www.aare.edu.au/04pap/alpha04.htm COR04942 (Erişim: 20.5.2009).

Çakan, M. (2004). Öğretmenlerin Ölçme-Değerlendirme Uygulamaları ve Yeterlik Düzeyleri: İlk ve Ortaöğretim. Ankara Üniversitesi Eğitim Fakültesi Dergisi, 37 (2), 99-114.

Dancer, W.T., \& Dancer, J. (1992). Peer rating in higher education. Journal of Education for Business, 67, 306-309.

De Corte, E. (2000). High-powered learning communities: A European perspective. The Economic and Social Research Council's Research 
Programme on Teaching and Learning Leicester, England, November 9-10, http://www.tlrp.org/acadpub/Corte2000.pdf (Erişim: 11.4.2008).

Dirkes, M. A. (1985). Metacognition: Students in charge of their thinking. Roeper Review, 8(2), 96-100.

Dochy, F. \& McDowell, L. (1997) Assessment as a toot for learning, Studies in Educational Evaluation, 23, 279-298.

Dochy, F. \& Moerkerke, G. (1997). The present, the past and the future of achievement testing and performance assessment. International Journal of Educational Research, 27(5), 415-432.

Dochy, F., Segers M., \& Sluijsmans, D. (1999). The Use of Self, Peer and Co-assessment in Higher Education: a review. Studies in Higher Education. 24(3).

Driver, R., Aasoko, H., Leach, J., Mortimer, E. \& Scott, P. (1994). Constructing scientific knowledge in the classroom. Educational Researcher, 23 (7), 5-12.

Duban, N. ve Küçükyılmaz, E.Y. (2008). Sınıf Öğretmeni Adaylarının Alternatif Ölçme- Değerlendirme Yöntem ve Tekniklerinin Uygulama Okullarında Kullanımına ilişkin Görüşleri. İlköğretim Online. 7(3), 769784 ,

Dutt-Doner, K. \& Gilman, D. A. (1998). Students React to Portfolio Assessment. Contemporary Education, 69(3).

Edgerton, E., \& McKechnie, J. (2002) Students' views of group-based work and the issue of peer assesment. Psychology Learning and Teaching, 2(2), 76-81

Ediger, M. (2000). Assessment with Portfolio and Rubric Use. ERIC Dökümanı Servis Numarası: ED 440127.

Edwards, R., Ranson, S. \& Strain, M. (2002). Reflexivity: towards a theory of lifelong learning. International Journal of Lifelong Education, 21, 525-536.

Erdoğan, T. (2006). Yabancı Dil Öğretiminde Portfolyoya Dayalı Değerlendirmenin Öğrenci Başarısı ve Derse Yönelik Tutumlarına Etkisi. Yayımlanmamış Yüksek Lisans Tezi. Dokuz Eylül Üniversitesi.

Ernest, P. (1995). The one and the many. In L. Steffe \& J. Gale (Eds.). Constructivism in education. New Jersey: Lawrence Erlbaum Associates,Inc.

Falchikov, N. (1986). Product comparisons and process benefits of collaborative peer group and self-assessments, Assessment and Evaluation in Higher Education, 11, 146-166.

Falchikov, N. (1995) Peer feedback marking: developing peer assessment, Innovations in Education and Training International, 32, pp. 175-187. 
Falchikov, N. \& Boud, D. (1989) Student self-assessment in higher education: a meta-analysis, Review of Educational Research, 59, 395430.

Faust, M. A. \& Kieffer, R, D. (1995). Portfolio Process: Teachers Exploring Assessment Alternatives. Final Report. ERIC Dokümanı, Servis Numarasi: ED 392805.

Fenwick, T. J. \& Parsons, J. (1999). Using Portfolios to Assess Learning. ERIC Dökümanı Servis Numaras1: ED 428398.

Freeman, M. (1995) Peer assessment by groups of group work, Assessment and Evaluation in Higher Education, 20, 289-300.

Flavell, J. (1979). Metacognition and cognitive monitoring: A new area of cognitive-developmental inquiry. American Psychologist, 34, 906-911.

Flavell, J. H. (1987). Speculations about the nature and development of metacognition. In F. E. Hargreaves, A., Lorna, E. ve Schmidt, M. (2002). Perspectives on alternative assessment reform. American Educational Research Journal. 39 (1), 69-95.

Fosnot, C. (1996). Constructivism: A Psychological theory of learning. In C. Fosnot (Ed.) Constructivism: Theory, perspectives, and practice. New York: Teachers College Press.

Gelbal. S., ve Kelecioğlu, H. (2007). Öğretmenlerin Ölçme Değerlendirme Yöntemleri Hakkındaki Yeterlik Algıları Ve Karşılaştıkları Sorunlar. Hacettepe Üniversitesi Eğitim Fakültesi Dergisi,33

Gergen, K. (1995). Social construction and the educational process. In L. Steffe \& J. Gale (Eds.). Constructivism in education. New Jersey: Lawrence Erlbaum Associates, Inc.

Greaves, J. D. \& Gupta, S. K. (2003). Portfolios can Assist Reflective Practice and Guide Learning. Current Anaesthesia and Critical Care, 14(4), 173-177.

Gomez, E. (2000). Assessment Portfolios: Including English Language Learners in Large-Scale Assessments. ERIC Doküman1, Servis Numaras1: ED 447725.

Grace, C. (1992). The Portfolio and Its Use: Developmentally Appropriate Assessment of Young Children. ERIC Dökümanı Servis Numarası: ED 351150 .

Güven, B., \& Eskitürk, M. (2007). Sınıf Öğretmenlerinin Ölçme ve Değerlendirmede Kullandıkları Yöntem ve Teknikleri. XVI. Ĕgitim Bilimleri Kongresi Bildiri Kitabı (504-509), Cilt 3, Ankara: Detay Yayıncilik.

Hamilton, L. S. (1994). Validating Hands-on Science Assessments Through an Investigation of Response Process. ERIC Doküman1, Servis Numaras1: ED 376202. 
Hall, K. (1995). Co-assessment: participation of students with staff in the assessment process. A report of work in progress, paper given at the 2nd European ElectronicConference on Assessment and Evaluation, http://listserv.surfnet.nl/archives/earli-ae.html(Erişim:10.04.2007)

Hebert, E. A. \& Schultz, L. (1996). The Power of Portfolios. Educational Leadership, 53(7), 70-71.

Heylighen, F. (1993). "Selection Criteria for the Evolution of Knowledge", in: Proc. 13th Int. Congress on Cybernetics (Association Internat. De Cybernétique, Namur), 524-528.

Honebein, J. (1996). Seven Goals for the Design of Constructivist Learning. http://cter.ed.uiuc.edu/JimL_Courses/edpsy490i/su01/readings/honebein .htm, (Erişim: 15.6.2008).

Horgan, D.D., Bol, L. \& Hacker, D. (1997). An examination of the relationships among self, peer, and instructor assessments, paper presented at the European Association for Research on Learning and Instruction, Athens, Greece.

Jonassen, D. H. 1994. Towards a Constructivist Design Model. Educational Technology, 34(4), 34-37.

Kaufman, D.B., Felder, R.M., \& Fuller H. (1999). Peer Ratings in Cooperative Learning Teams. Proceedings of the 1999 Annual ASEE Meeting. ASEE, June 1999 Session 1430.

Keaten, J.A. \& Richardson, M.E. (1992). A field investigation of peer assessment as part of the student group grading process, paper presented at the Western Speech Communication Association Convention, Albuquerque, NM.

Kutlu, Ö., Doğan, C.D. ve Karakaya, İ.(2008). Öğrenci Başarısının Belirlenmesi: Performansa ve Portfolyaya Dayalı Durum Belirleme. Pegem A Yayıncılık, Ankara.

Kutlu, Ö., Yıldırım, Ö. ve Bilican, S. (2009). Öğretmenlerin Dereceli Puanlama Anahtarına İlişkin Tutum Ölçeği Geliştirme Çalışması. Yüzüncü Yıl Üniversitesi, Eğitim Fakültesi Dergisi.6(2), 76-88

Lejk, M., \& Wyvill, M. (2001). Peer Assessment of Contributions to a Group Project: a comparison of holistic and category-based approaches. Assessment \& Evaluation in Higher Education, 26(1), 61-72

Lourdusamy, A., \& Divaharan, S. (2000). Peer assessment in higher education: Students' perceptions and its reliability. Journal of Applied Research in Education, 4(1), 81-93.

Magin, D. (2001). Reciprocity as a source of bias in multiple peer assessment of group work. Studies in Higher Education, 26, 53-63. 
MEB. (2003). Öğrenci Merkezli Eğitim Uygulama Modeli, Millî Eğitim Basım Evi, Ankara (192-205).

McDowell, L. (1995). The impact of innovative assessment on student learning, Innovations in Education and Training International, 32, 302313.

McMahon, T. (2009). Combining peer-assessment with negotiated learning activities on a day-release undergraduate-level certificate course (ECTS level 3). Assessment \& Evaluation in Higher Education, 1-17,

Moya, S. S. \& O’Malley, J. M. (1994). A Portfolio Assessment Model for ESL. The Journal of Educational Issues of Language Minority Students, 13, 13-36.

Mullin, J. A. (1998). Portfolios: Purposeful Collections of Student Work. New Directions for Teaching and Learning, 74.

Oldfield, K.A., \& Macalpine, J.M.K. (1995). Peer and self-assessment at the tertiary level- an experiential report. Assessment and Evaluation in Higher Education, 20, 125-132.

Orsmond, P., Merry, S., \& Reiling, K. (1996). The importance of marking criteria in the use of peer assessment. Assessment and Evaluation in Higher Education, 21, 239-249.

Öncü, H. (2009). Ölçme ve Değerlendirmede Yeni Bir Yaklaşım: Portfolyo Değerlendirme. Türkiye Sosyal Araştırmalar Dergisi.13(1), 103-130.

Oskay, Ö. Ö, Schallies M. \& Morgil, İ (2008). Reliability of Portfolio: A Closer Look at Findings From Recent Publications.H.U. Journal of Education. 35: 263-272

Parsons, D. E., \& Drew, S. K. (1996). Designing group project work to enhance learning: key elements. Teaching in Higher Education, 1, 6580.

Paulson, F.L., Paulson, P.R. \& Meyer, C.A. (1991). What Makes a Portfolio a Portfolio? Educational Leadership, 48(5), 60-63.

Perkins, D. (1999). The Many Faces of Constructivism, Educational Leadership, 57(3), 6-11

Pickard J. M. (2007). The new Bloom's taxonomy: Aa overview for family and consumer sciences. Journal of Family and Consumer Sciences Education, 25(1)

Pierce, L. V. \& O'Malley, J. M. (1993). Performance and Portfolio Assessment for Language Minority Students. Educational Evaluation and Policy Analysis, 15(3)

Pond, K., Ul-Haq, R. \& Wade, W. (1995). Peer review: a precursor to peer assessment, Innovations in Education and Training International, 32, 314-323. 
Purchase, H. C. (2000). Learning about interface designs through peer assessment. Assessment \& Evaluation in Higher Education, 25(4), 341352.

Shen, C., \& Pedulla, J. J. (2000). The Relationship between Students' Achivement and their Self-perception of Competence and Rigour of Mathematics and Science: a cross-national analysis. Assessment in Education, 7(2), 237-253.

Shrauger, S. J. \& Osberg, T. M. 1981. The relative accuracy of selfprediction and judgements by others in psychological assessment. Psychological Bulletin, 90, 322-351.

Somervell, H. (1993). Issues in assessment, enterprise and higher education: the case for self-, peer and collaborative assessment, Assessment and Evaluation in Higher Education, 18, 221-233.

Stefani, A.J. (1992). Comparison of collaborative, self, peer and tutor assessment in a biochemistry practical, Biochemical Education, 20, $148-151$.

Strachan, I.B. \& Wilcox, S. (1996). Peer and self-assessment of group work: developing an effective response to increased enrolment in a third-year course in microclimatology, Journal of Geography in Higher Education, 20, 343-353.

Sundström, A. (2005). Self-assessment of knowledge and abilities: A literature study. Umea Universitet, 54.

Türk Dil Kurumu, (2011). Büyük Türkçe Sözlük. http://tdkterim.gov.tr/bts/ (Erişim: 16.01.2011)

Tedick, D. J. \& Klee, C. A. (1998). Alternative Assessment in the Language Classroom. ERIC Doküman1, Servis Numarası: ED 433720.

Topping K. J. (1998). Peer-assessment between students in colleges and universities, Review of Educational Research, 68, 249-276.

Topping K. J. (2005). Trends in Peer Learning. Educational Psychology, 25(6),631-645

Valencia, S. (1990). A Portfolio Approach to Classroom Reading Assessment: The Whys, Whats, and Hows. The Reading Teacher, 43(4), 38-40.

Van den Berg I., Admiraal W. \& Pilot A. (2006) Design principles and outcomes of peer assessment in higher education. Studies in Higher Education, 31( 3), 341-356

Von Glasersfeld, E. (1989). Cognition, construction of knowledge, and teaching. Synthese, 80(1), 121-140.

Weaver II. R., \& Cotrell, H.W. (1986) Peer evaluation: a case study, Innovative Higher Education, 11, 25-39. 
Wilson, B. G., \& Cole, P. 1991. A review of cognitive teaching models. Educational Technology Research \& Development Journal. http://carbon.ucdenver.edu/ bwilson/hndbkch.html (Erişim: 20.5.2009).

Wolf, Kenneth \& Siu-Runyan, Yvonne (1996). Portfolio Purposes and Possibilities. Journal of Adolescent \& Adult Literacy, 40,(1).

Yueh J. \& Alessi, S.M. (1988). The effect of reward structures and group ability composition on cooperative computer-assisted instruction. Journal of Computer-Based Instruction, 15(1), 18-22.

Yurdabakan, İ. (2008). Eğitimde Kullanılan Ölçme Araçlarının Nitelikleri. Erkan, S. ve Gömleksiz, M., (Ed.), Ĕgitimde ölçme ve değerlendirme. (38-66) . Ankara: Nobel Yayın Dağıtım.

Yurdabakan, İ. (2010). The investigation of peer assessment in primary school cooperative learning groups with respect to gender. Education 313. DOI: $10.1080 / 03004270903313608$

Zollman, A. ve Jones, D. L. (1994). Accomodating Assessment and Learning: Utilizing Portfolios in Teachers Education with Preservice Teachers. ERIC Dokümanı, Servis Numarası: ED 368551. 
